\title{
Effect of Oil Paint Addition on Micro Hardness of Acrylic Ocular Prosthesis
}

\author{
Firas Abd Kati \\ (Assistant Lecturer) - College of Health \& Medical Technology / Middle Technical University \\ Arshad F. Jassem Al-Kaabi \\ (Assistant Lecturer) - College of Health \& Medical Technology / Middle Technical University
}

\begin{abstract}
Introduction: Medical grade acrylic resin is the material of choice for many dental and facial restorations. When making artificial eye from this polymer, it is highly required to apply the perfect shade matching the original one. However, this may have some significant effect on the mechanical properties as well as surface integrity since most types of paints used with acrylic resin are oil paints. The aim of this study was to evaluate the effect of oil paint addition on acrylic resin surface hardness.

Methods: The study consisted of 3 main groups (control, white 1, and white 2). Each group consisted of 10 samples. The paint concentration was increased from white 1 to white 1 respectively. Vickers hardness test was applied on all samples.

Results: The statistical results showed that there was a significant increase in the acrylic surface hardness as the oil paint concentration increases ( $p$-value $<0.05$ ).

Conclusion: A conclusion drawn from this study that the oil paint would have significantly increase the acrylic eye prosthesis hardness but it might be to a certain level.
\end{abstract}

KEYWORDS

ocular prosthesis; acrylic resin coloring; acrylic resin surface hardness.

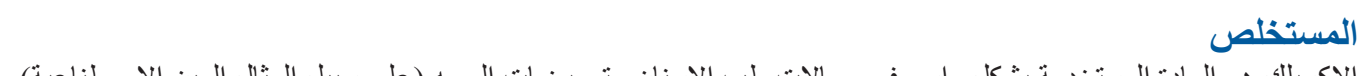

الاكريلك هو المادة المستخدمة بشكل واسع في مجالات طب الاسنان وتعويضات الوجه (على سبيل المثال العين الاصطناعية).

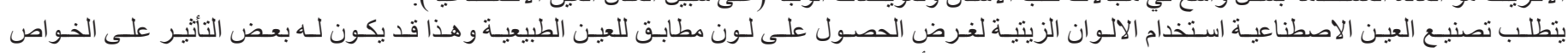

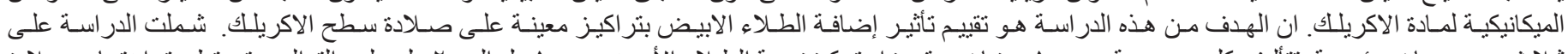

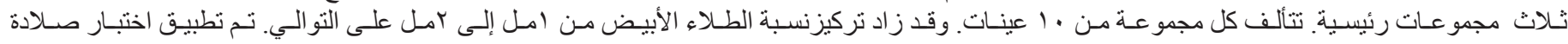
في جميع العينـات. النتائج: أظهرت العنات النتائج أن هنالك زيادة كبيرة في صلادة سطح الاكريلك مع زيادة تركيز الطلاء.

\section{INTRODUCTION}

Ocular prosthesis refers to the object that is manufactured from glass or plastic materials to replace the missing eye. Since one of the first noticeable features of the human face is the eye (1), any deformity or defect that has a congenital or accidental origin would significantly impact both the physiological and the psychological status of the individual ${ }^{(2,3)}$ It is suggested to replace the lost eye as soon as possible in order to avoid the patient stress due to the societal reaction to the patient's deformity (4). The biggest challenges associated with ocular prosthesis treatment is to make the patient capable of coping with the rehabilitation process which would enhance its esthetic acceptability ${ }^{(5)}$. Regarding esthetics, ocular prosthesis are mainly made from medical grade acrylic resin (polymethylmethacrylate) in a process involving proper shaping and adding white stain as well as blood vessel simulation to match the appearance of the natural eye ${ }^{(6)}$. When it comes to coloring, different materials are used to for this purpose such as hydrosoluble gouache and nitrocellulose that are chemically compatible with acrylic resin. However, the main type of stain used is the oil paint ${ }^{(7,8)}$. It was reported in the literature that color combination with the acrylic resin would have some effects on the mechanical properties of the resin itself ${ }^{(9)}$. Oil paint addition would have an optimum esthetic results for the restoration due to their compatibility with the acrylic resin. However, oil acts as a plasticizer that could change the mechanical properties of the final restoration which might later affect its color stability ${ }^{(10,11)}$. Therefore, it is necessary to understand what kind of change the oil paint addition would happen on the acrylic resin surface properties as well as the mechanical properties. The aim of this study was to evaluate the effect of oil paint addition on acrylic resin surface hardness.

\section{MATERIALS AND METHODS Materials}

In this study, a total of 30 specimens of acrylic resin (Spofadental,Czech Republic) were used. They were divided into 3 groups; the control, white 1 , and white 2. Each group had 10 specimens. The experimental groups (white 1 and white 2 ) differ from each other in the amount of white oil paint added. The oil paint used was Grumbacher Titanium white (USA)(Picture 1). Dental stone (Spofadental,Czech Republic) was used for molds making, and petroleum 
jelly (China) was used as a separating medium.

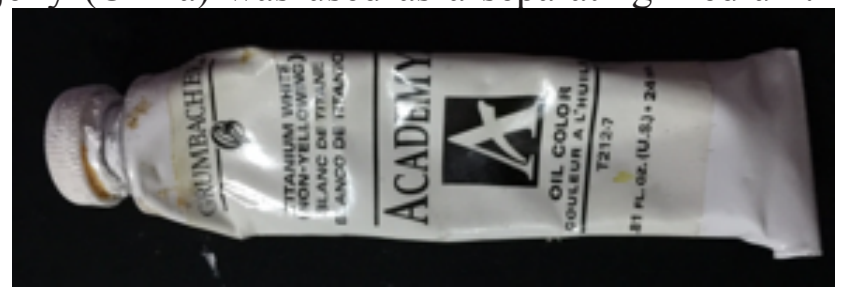

Picture (1): Oil paint (acrylic compatible) Grumbacher Titanium white

\section{Sample preparation}

Metal models (65 mm x $10 \mathrm{~mm}$ x $3 \mathrm{~mm}$ ) were used to make acrylic samples. The sample preparation started by applying separating medium to the upper and lower halves of metal flask to facilitate removal of stone mold following deflasking. Then, the mixed dental stone at a creamy state was placed into lower half of flask and patterns gently in the middle part while taking into consideration half of patterns must be exposed so that they can be easily removed. After complete set of the dental stone layers, the separating medium was added and upper half was placed into its position. Another mix of dental stone was prepared and placed over both patterns and stone surface. The mold was left for one hour. It was then opened to remove the metal sample (Picture 2). After that, the mold was lubricated with separating medium and left to dry. The second layer of the medium was applied. The acrylic powder and liquid were mixed for the control group by adding $22 \mathrm{~g}$ of the powder to $10 \mathrm{ml}$ of the monomer at each mix. The dough acrylic was packed into the mold, the flask was compressed under hydraulic press and then cured. Once curing completed, the flask was left to cool. The samples were removed from the flask, finished and polished. They were then stored in water to avoid acrylic shrinkage until conducting the hardness test.

The White acrylic samples (groups 2 and 3) were fabricated using the above process with adding $1 \mathrm{ml}$ white oil paint to $9 \mathrm{ml}$ liquid monomer for the White 1 group, and adding $2 \mathrm{ml}$ white oil paint to $8 \mathrm{ml}$ of monomer for the White 2 group.

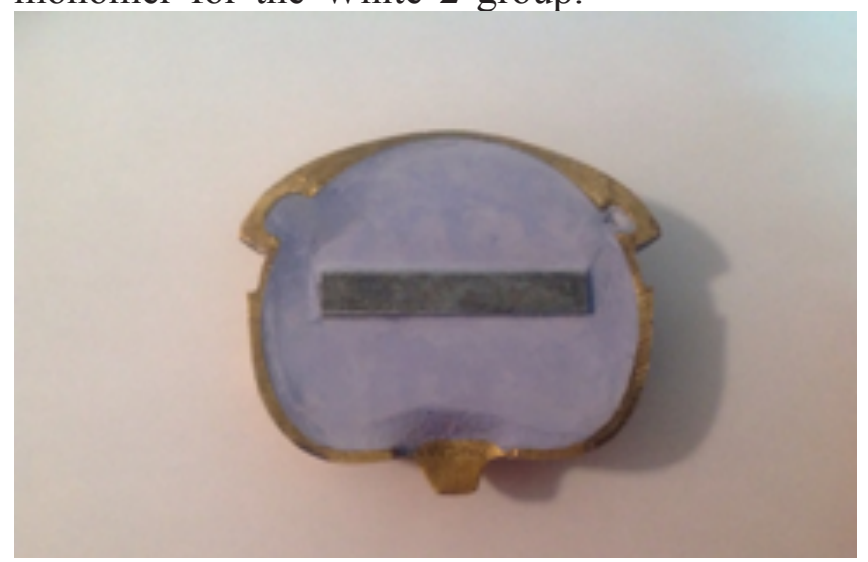

Picture (2): The dental stone mold and the metal model

\section{Hardness test}

Hardness tester (Matsuzawa Japan for Vickers hardness test) was used for measuring acrylic samples' hardness and the Vickers micro-hardness test was selected according to the samples' material (Picture 3). The test protocol consist of applying a load of 50 grams on the sample surface for 10 seconds. The samples were tested three times (left, middle, right) and average readings were calculated for each specimen.

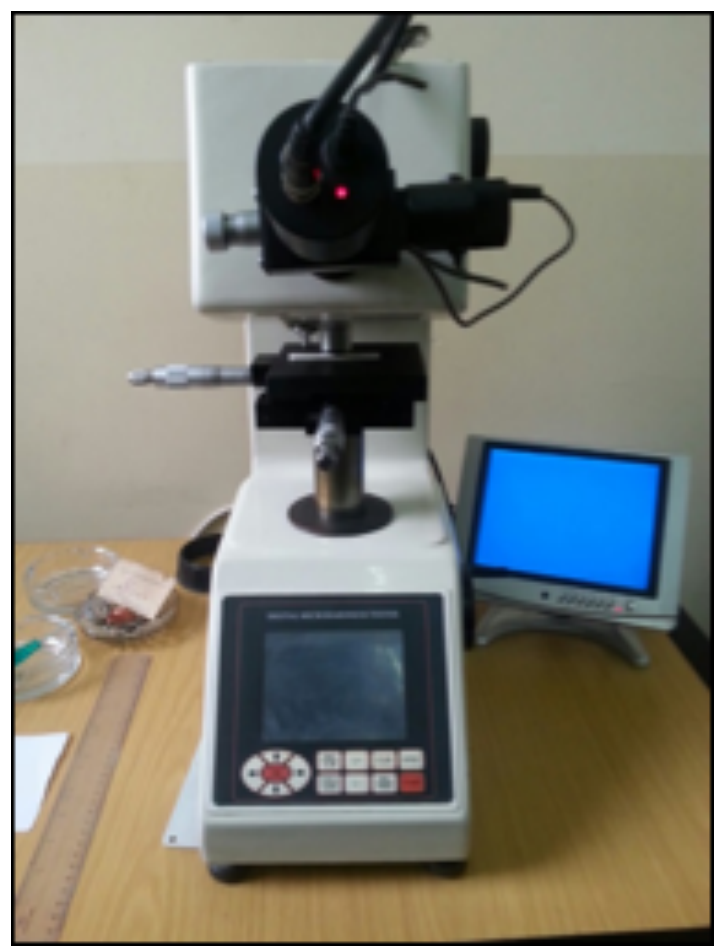

Picture (3): Matsuzawa hardness testing machine

\section{RESULTS}

Each sample was subjected to Vickers hardness test for three times at three different spots. An average value for the three different measurements was calculated to represent the sample hardness strength. The IBM SPSS V.20 software was used for the statistical analysis. As presented in Tables (1 and 2 ), there was a noticeable increase in the mean values of hardness strength as the concentration of the oil paint increases. That was associated with the slight but insignificant increase in the standard deviation values for the white 1 and the white 2 groups. The One-way ANOVA test confirmed the tendency of the oil paint to increase the hardness strength of the acrylic resin material $\mathrm{P}$-value $<0.05$ as both white 1 and 2 were significantly different in the amount of hardness strength than the control. They were also significantly different from each other in the amount of hardness strength as illustrated in the Tukey HSD multiple comparison test (Table 3). 
Table (1): Hardness values for the groups' samples $\left(\mathrm{g} / \mathrm{mm}^{2}\right)$

\begin{tabular}{|c|c|c|}
\hline Control & White 1 & White 2 \\
\hline 129.60 & 226.00 & 245.40 \\
\hline 128.40 & 230.40 & 243.80 \\
\hline 130.70 & 225.30 & 246.30 \\
\hline 126.50 & 227.20 & 249.60 \\
\hline 128.30 & 229.80 & 250.40 \\
\hline 127.60 & 231.50 & 241.50 \\
\hline 131.20 & 219.20 & 242.20 \\
\hline 125.90 & 228.40 & 243.30 \\
\hline 124.20 & 231.20 & 248.20 \\
\hline 123.80 & 230.90 & 247.80 \\
\hline
\end{tabular}

Table (2): Means and standard deviation values for the groups

\begin{tabular}{|l|c|c|c|c|}
\hline & Groups & $\boldsymbol{N}$ & Mean & Std. Deviation \\
\hline \multirow{2}{*}{$\begin{array}{l}\text { Hardness } \\
\left(\mathrm{g} / \mathrm{mm}^{2}\right)\end{array}$} & Control & 10 & 127.62 & 2.53412 \\
\hline & White 1 & 10 & 227.99 & 3.79223 \\
\hline & White 2 & 10 & 245.85 & 3.11707 \\
\hline
\end{tabular}

Table (3): Tukey HSD multiple comparison test (ANOVA)

\begin{tabular}{|c|c|c|c|c|}
\hline \multirow{2}{*}{ Groups } & \multirow{2}{*}{} & \multicolumn{3}{|c|}{ Subset for alpha $=\mathbf{0 . 0 5}$} \\
\cline { 3 - 5 } & & $\mathbf{1}$ & $\mathbf{2}$ & $\mathbf{3}$ \\
\hline Control & 10 & 127.6200 & & \\
\hline White 1 & 10 & & 227.9900 & \\
\hline White 2 & 10 & & & 245.8500 \\
\hline Sig. & & 1.000 & 1.000 & 1.000 \\
\hline
\end{tabular}

DISCUSSION

Acrylic resin material (polymethylmethacrylate) has been used extensively for a variety of medical applications due to its chemical and mechanical properties as well as being biologically inert when it is used for making a dental or facial prosthesis. When it comes to ocular prosthesis which is mainly constructed from acrylic resin, it is necessary to evaluate the functionality and the suitability of this material as well as its longevity. Acrylic eyes need to match the real ones as much as possible. Therefore, several paints and stains are used for prosthetic coloring. Since oil paints are the material of choice for most technicians, it is believed that it might have an effect on the mechanical properties of the acrylic restoration since oil paint acts as a plasticizer. The aim of this study was to examine and evaluate the effect of oil paint addition to the acrylic resin on its surface hardness. Three study groups were used; the control and 2 different paint-loaded groups. The Vickers hardness test results showed a significant variation among the groups with the increase in surface hardness as the oil paint concentration increases. The statistical results demonstrate the surface hardness increase in relation to oil paint concentration. The study results disagrees with a study conducted by Parker S. and associates [12] who stated that surface hardness of soft acrylic resin decreases with the increase of plasticizer content which is oil soluble compound.

\section{CONCLUSION}

This study was an attempt to evaluate the effect of oil paint addition on the acrylic resin (polymethylmethacrylate) material in terms of hardness strength. The study results clearly stated that the oil paint would significantly increase the hardness strength of the acrylic resin. However, it is still ambiguous that at what lever of oil paint concentration this hypothesis would still valid. Therefore, further considerations are highly recommended.

\section{REFERENCES}

1. Doshi PJ, Aruna B. Prosthetic Management of patient with ocular defect. J Ind Prosthodont Soc 2005; 5: 37-38.

2. Lubkin V, Sloan S. Enucleation and psychic trauma. Adv Ophthalmic Plast Reconstr Surg 1990; 8: 259-262.

3. Raflo GT. Enucleation and evisceration. In: Tasmun W, Jaeger E eds. Duane's Clinical Ophthalmology, Revised edn, Vol. 5. Philadelphia: Lippincott-Raven, 1995: 1-25.

4. Artopoulou II, Montogomery PC, Wesley PJ, Lemon JC. Digital imaging in the fabrication of ocular prostheses. $J$ Prosthet Dent 2006; 95: 327-330.

5. Ow RKK, Amrith S. Ocular prosthetics: use of a tissue conditioner material to modify a stock ocular prosthesis. J Prosthet Dent 1997; 78: 218-222.

6. Benson $\mathrm{P}$. The fitting and fabrication of a custom resin artificial eye. J Prosthet Dent 1977; 38: 532-538.

7. Fernandes AU, Goiato MC, Batista MA, Santos DM. Color alteration of the paint used for iris painting in ocular prostheses. Braz Oral Res. 2009 Oct-Dec;23(4):386-92.

8. Rutkunas V, Sabaliauskas V, Mizutani H. Effects of different food colorants and polishing techniques on color stability of provisional prosthetic materials. Dent Mater J. 2010 Mar;29(2):167-76.

9. Heath JR, Wilson HJ. Surface roughness of restorations. $\mathrm{Br}$ Dent J 1976; 140: 131-137.

10. Wright PS. Composition and properties of soft lining materials for acrylic dentures. J Dent 1981;9:210-23.

11. Braden M, Wright PS. Water absorption and water solubility of soft lining materials for acrylic dentures. J Dent Res 1983; 62:764-8.

12. Parker S, Martin D, Braden M. Soft acrylic resin materials containing a polymerisable plasticiser I: mechanical properties. Biomaterials. 1998 Sep;19(18):1695-701. 